\title{
Learning Model AIK 1 (Aqidah) in College Based on Educations Velue
} Model Pembelajaran AIK I (Aqidah) Di
Perguruan Tinggi Berbasis Pendidikan Nilai

\author{
Mir'atun Nisa'* \\ Studi IImu Keperawatan, UMY, Universitas Muhammadiyah Yogyakarta, Yogjakarta, Indonesia
}

The challenges of al-Islam and Muhammadiyah Education or abbreviated as AIK include the curriculum that is not yet fully in line with Muhammadiyah's vision and mission, not yet balanced between affective cognitive and personality, unstructured material and structured learning material that is dense but does not have a spirit or meaning. Various studies have been conducted an effort to advance AlK education which is more striking but AlK related research is still theoritical and methodological approach. So that this article gives the colors of AlK learning models based on educational values. Based on these objectives, this article uses the literature literary method with sources that support the AlK curriculum in the AlK Education Guidelines for the Muhammadiyah Council of DikTi PP. The result of this article is education syllabi of AlK that more practical and implementative. Through this assessment, the lecturer can instill beneficial values in students in accordance with increasing faith and Islamic values as an increase of applicable learning.

Keywords: al-Islam and Muhammadiyah education, syllabi, values education

OPEN ACCESS

ISSN 2723-3774 (online)

Edited by:

Puspita Handayani

Reviewed by:

Khozin

${ }^{*}$ Correspondence:

Mir'atun Nisa'

Miratunnisa@umy.ac.id

Received: 20 Desember 2019

Accepted: 5 Maret 2020

Published: 25 Agustus 2020

Citation:

Nisa' M (2020) Learning Model AlK

1 (Aqidah) in College Based on

Educations Velue.

Model Pembelajaran AIK I (Aqidah)

Di Perguruan Tinggi Berbasis

Pendidikan Nilai . 1:2.

doi: 10.21070/jims.v1vi2i. 1054
Tantangan Pendidikan AlK atau al-Islam dan KeMuhammadiyahan antara lain disebabkan adanya kurikulum yang belum sepenuhnya sesuai dengan visi misi Muhammadiyah, belum seimbang antara kognitif afektif dan kepribadian, materi yang belum sistematis dan terstruktur juga materi pembelajaran yang padat tapi tidak memiliki ruh atau makna. Berbagai penelitian telah dilakukan dalam kerangka memajukan pendidikan AIK yang lebih mengena tetapi penelitian terkait AIK masih bersifat teoritis dan metodologis sehingga tulisan ini bertujuan memberikan warna model pembelajaran AlK berdasar pendidikan nilai. Atas dasar tujuan tersebut, artikel ini menggunakan metode literatur kepustakaan dengan sumber utamanya adalah kurikulum pendidikan AlK dalam buku Pedoman Pendidikan AIK Majelis DikTi PP Muhammadiyah. Hasil tulisan ini berupa rancangan silabi pendidikan AIK I berisi Aqidah dengan pendekatan nilai dan teori living values education. Pendekatan ini dapat diterapkan dalam pendidikan AIK I yang lebih praktis dan implementatif. Melalui pendekatan ini dosen dapat menanamkan nilai-nilai kebaikan dalam pribadi mahasiswa seiring dengan semakin tertanamnya keimanan dan nilai-nilai kelslaman sebagai dampak dari pembelajaran yang aplikatif.

Keywords: al-Islam dan pendidikan Muhammadiyah, syllabi, pendidikan nilai 


\section{PENDAHULUAN}

Pendidikan AIK (Singkatan dari al-Islam dan KeMuhammadiyahan) dapat dikatakan menjadi ciri khas pendidikan agama Islam di Perguruan Tinggi Muhammadiyah. Selaras dengan undang-undang Nomor 20 Tahun 2003 tentang Sistem Pendidikan Nasional bahwa pendidikan adalah usaha sadar dan terencana untuk mewujudkan suasana dan proses pembelajaran yang mendorong peserta didik untuk aktif mengembangkan potensi diri agar memiliki kekuatan spiritual keagamaan, kepribadian, kecerdasan, pengendalian diri, akhlaq mulia serta memiliki keterampilan yang bermanfaat bagi diri, masyarakat dan negara. 20 (2003) Pendidikan AIK pun bertujuan mencetak insan terpelajar, berkarakter, berjiwa pengasih pada sesama, memiliki kesadaran etis dan integritas. Muhammadiyah (2011) Demi mencapai tujuan-tujuan tersebut, materi pokok pendidikan AIK diarahkan pada materi keIslaman meliputi sumber utama ajaran Islam yakni al-Qur'an dan Hadis, materi aqidah, akhlaq, fiqih dan wawasan keMuhammadiyahan.

Tantangan yang dihadapi oleh perguruan tinggi dalam memformulasikan pendidikan AIK menjadi sebuah pembelajaran dengan tujuan dan materi-materi tersebut antara lain kurikulum dan silabi. Majelis Pendidikan Tinggi Pimpinan Pusat Muhammadiyah (DikTi PP) merumuskan beberapa permasalahan terkait pendidikan AIK dari sisi kurikulumnya antara lain; desain kurikulum AIK yang belum maksimal sesuai visi dan misi Muhammadiyah, arah pendidikan yang dominan kognitif sehingga belum seimbang antara kognitif-afektif dan kepribadian, materi belum sistematis berjenjang sehingga terjadi pengulangan di setiap jenjang, materi belum terstruktur secara sistematis antara silabi, metode, tehnik dan evaluasi, juga materi yang banyak dan padat tetapi kurang bermakna. Muhammadiyah (2011) Permasalahan itulah yang masih harus dievaluasi oleh PTM terkait AIK.

Upaya mengurai dan mencari solusi dari permasalahan tersebut telah dilakukan oleh pemerhati studi AIK dengan berbagai penelitian seperti yang dilakukan oleh Andriyani dkk tentang implementasi kurikulum AIK di FKIK Universitas Muhammadiyah Jakarta dengan model Student Centered Learning (SCL). Model SCL ini meminimalkan peran dominan dosen (Teacher Centered Learning) dan memaksimalkan peran aktif mahasiswa dengan menggunakan tiga tehnik pembelajaran berupa kuliah pendahuluan dengan tetap mengedepankan komunikasi dua arah. Teknik kedua dalam bentuk tutorial dengan model PBL (Problem Based Learning). Andriyani et al. (2014a) Tehnik ketiga dalam bentuk keterampilan atau teknik ISL. Inti temuan penelitiannya bahwa model SCL mampu meningkatkan motivasi dan kemandirian mahasiswa dalam proses belajar AIK. Penelitian Andriyani dkk dapat menjadi inspirasi dan ide model pembelajaran yang efektif, hanya saja penelitian ini bersifat teoritis metodologis sehingga belum tergambar pembelajaran AIK secara aplikatif. Penelitian lain dilakukan oleh Syamsul Arifin tentang AIK yang butuh untuk direkonstruksi menjadi praksis pendidikan nilai di Perguruan Tinggi Muhammadiyah. Arifin melakukan riset kurikulum AIK di UMM yang dibagi menjadi beberapa dekade. Ia menawarkan paradigm pendidikan AIK sebagai praksis pendidikan nilai. Sederhananya, pendidikan AIK bertujuan untuk memberikan nilai-nilai Islami kepada mahasiswa bukan mencetak mahasiswa menjadi ahli keagamaan. Nilai yang dimaksud adalah standar acuan baik dan buruk yang harus dilakukan atau dijauhi. Standar acuannya dapat merujuk pada pemikiran Nurcholis Madjid tentang dua dimensi nilai dalam pendidikan agama yakni ketuhanan dan kemanusiaan. Arifin di akhir tulisannya menyarankan adanya pendidikan AIK yang dapat menghidupkan dua dimensi nilai tersebut dalam bentuk living values education. Ia berharap adanya sistem tersebut yang bisa dimulai dari peran dosen di perguruan tinggi. Arifin (2015) Studi kasus yang dilakukan Arifin baru pada tahap opini untuk melakukan pendidikan AIK sebagai pendidikan nilai praksis akan tetapi belum memberikan tawaran secara aplikatif. Pada kesempatan lain, Zalik Nuryana menawarkan adanya Revitalisasi pendidikan AIK di perguruan tinggi Muhammadiyah. Revitalisasi didasarkan pada adanya anggapan terhadap AIK yang dipandang sebelah mata sehingga penting untuk melakukan dua hal yaitu memunculkan pendidian AIK bagi perguruan tinggi yang belum mengadakan pendidikan AIK dan memaksimalkan peran AIK di perguruan tinggi yang telah melaksanakannya. Andriyani et al. (2014b) Tulisan Zalik lebih mengarah pada peran AIK di perguruan tinggi dan tidak memberikan tawaran bagaimana peran AIK yang lebih praksis. Banyak hal yang telah 
dilakukan untuk mendorong pendidikan dan pembelajaran AIK lebih baik dan lebih mengena termasuk yang telah dilakukan oleh Elihami dengan meningkatkan pembelajaran AIK melalui kuis. Elihami (2017) Berdasar penelitian-penelitian yang telah ada, masih dibutuhkan adanya ide-ide dan gagasan serta penelitian dalam pengembangan pendidikan dan pembelajaran AIK khususnya terkait kurukulum. Tujuan penulisan artikel ini adalah sebuah tawaran model pembelajaran AIK yang lebih praksis dan implementatif berdasar teori pendidikan nilai sebagai sebentuk solusi dari permasalahan-permasalahan pembelajaran AIK sebagaimana disebutkan diatas.

\section{METODE DAN TEHNIK PENULISAN}

Jenis penulisan ini adalah kepustakaan artinya data-data yang digunakan adalah data tertulis baik primer maupun sekunder. enulis menelaah data tentang silabus pembelajaran AIK di Perguruan Tinggi Muhammadiyah (PTM). Silabus yang diambil adalah silabus pembelajaran AIK I yakni difokuskan pada Aqidah. Data lain terkait pendidikan terutama pendidikan nilai dalam tulisan ini menjadi data-data pendukung.

Penulis melakukan penelaahan terhadap sumber yakni data silabus yang didapatkan dari buku Pedoman Pendidikan al-Islam dan KeMuhammadiyahan oleh Majelis Pendidikan Tinggi Pimpinan Pusat . Data-data terkait pendidikan karakter didapatkan dari buku,jurnal dan penelitian.

Setelah data terkumpul maka dilakukan pemaparan data tentang silabus sebagai objek material. Data tersebut dideskripsikan sedemikian rupa. Untuk memperoleh hasil yang memadai, data tersebut dianalisis dengan teori pendidikan nilai dan living values education. Agar memperoleh pemahaman yang memadai maka dideskripsikn terlebih dahulu tentang pendidikan nilai dan living values education.

Analisa data dilakukan dengan metode deskriptif analitis. Deskripsi ditujukan untuk memaparkan data secara interpretatif sedangkan analitis ditujukan untuk menguraikan data tersebut secara teoritis.

Bagian akhir penulisan akan dikemukakan kesimpulan dari hasil deskripsi dan analisa yang menghasilkan tawaran ide dan model sesuai tujuan.

\section{HASIL DAN PEMBAHASAN}

\section{AIK dan Pendidikan Nilai}

Sebagaimana tertuang dalam buku Pedoman Pendidikan AIK bahwa arah materi AIK adalah pengembangan karakter peserta didik menjadi manusia yang saleh, berbuat kebaikan dan kebajikan kepada sesama muslim maupun non muslim dengan isi pokok materi yang lebih menyentuh aspek-aspek kehidupan. Muhammadiyah (2011) Pertanyaan yang muncul adalah bagaimana karakter saleh itu dapat terwujud dan berkembang? Karakter adalah tabiat, akhlak, bentuk watak yang menyatu dalam diri seseorang. Pikiran dan tindakan yang khas dari seseorang adalah buah dari internalisasi ini. Agar karakter dapat berkembang secara terarah maka dibutuhkan proses pendidikan. Maunah (2016) Sayangnya, proses pendidikan yang berlangsung lebih banyak berorientasi pada penguasaan pengetahuan an sich dan pencapaian tujuan pembelajaran secara formalitas belaka sehingga kurang berorientasi pada pembentukan kepribadian dan watak peserta didik (character building). Nilai-nilai kebenarn, keadilan dan kemanusiaan selayaknya dimiliki oleh peserta didik dengan cara menumbuhkan karakter tersebut melalui proses pendidikan nilai. Subur (1970)

Nilai diterjemahkan oleh para ilmuwan dalam banyak definisi salah satunya adalah definisi yang dikemukakan oleh Harun Nasution bahwa nilai diartikan sebagai nilai rohani (etika religius) yang berupa keadilan, kejujuran, kesucian, berpikiran lurus, bersih hati, tolong menolong, persaudaraan, kesetiakawanan, murah hati, suka memberi maaf, pemurah, sabar, baik sangka, berani, berkata benar, mencintai ilmu, hemat, disiplin, menepati janji, [8] dari definisi tersebut dapat diketahui bahwa nilai adalah prinsip-prinsip yang diajarkan oleh agama yang harus senantiasa dilekatkan dalam diri pribadi seseorang. Nilai bersifat realitas abstrak yang 
berfungsi sebagai tolok ukur dan standar bagi tingkah laku manusia berkaitan dengan baik atau buruk dan sebagainya.

Dalam ilmu pendidikan dikenal adanya living values education (selanjutnya disingkat LVE) dimana pendidian difungsikan untuk menggali dan mengembangkan nilai-nilai universal juga menerapkannya dalam kehidupan keseharian. Nilai-nilai tersebut dikategorikan dalam 12 nilai meliputi;

1. Kedamaian, yakni perkataan, perbuatan atau tindakan yang membuat orang lain merasa tentram dan bahagia.

2. Kedamaian, yakni perkataan, perbuatan atau tindakan yang membuat orang lain merasa tentram dan bahagia

3. Penghargaan, yakni sikap perbuatan yang memotivasi peserta didik untuk melakukan sesuatu yang bermanfaat bagi lingkungan masyarakat dan menghormati keberhasilan orang lain.

4. Cinta, yakni sikap perbuatan membantu orang lain dan komunitas orang-orang yang membutuhkan.

5. Toeransi yakni sikap perbuatan yang menghormati perbedaan ras, agama, suku, pemikiran, sikap yang berbeda dari diri mereka sendiri.

6. Kejujuran, yakni perbuatan yang memicu peserta didik untuk senantiasa menjadi pribadi yang selalu percaya pada kata-kata, perbuatan dan pekerjaannya.

7. Kerendahan hati, yakni sikap menerima kelebihan dan kekurangan diri sendiri maupun orang lain.

8. Kerjasama, yakni kemampuan menjalin kerjasama dengan orang lain .

9. Kebahagiaan, yakni perbuatan yang menunjukkan rasa kesenangan dan kegembiraan.

10. Tanggungjawab, yakni sikap perbuatan seseorang untuk melakukan tugas untuk diri sendiri, lingkungan (alam, sosial, dan budaya), masyarakat, bangsa dan negara serta Tuhan Yang Maha Esa

11. Kesederhanaan, yakni sikap dan perbuatan yang bersahaja (tidak berlebihan).

12. Kebebasan, yakni sikap dan perbuatan yang menunjukkan independensi sesuai aturan.

13. Persatuan yakni sikap yang menunjukkan persatuan dan kepentingan kolektif.[9] Komalasari and Sapriya (2016)

Selain nilai-nilai tersebut, LVE juga memiliki skema pembelajaran; pertama, stimulus nilai. Stimulus adalah memberikan pemantik kepada peserta didik agar terpantik untuk melakukan nilai-nilai yang diinginkan. Tiga hal yang tercakup dalam stimulus nilai adalah refleksi internal, eksplorasi nilai-nilai dalam kehidupan nyata dan penerimaan informasi. Kedua, diskusi. Ketiga, eksplorasi ide dan gagasan. Keempat, ekspresi kreatif. Kelima, Pengembangan keterampilan personal, sosial maupun emosional. Keenam, peran dan tanggungjawab dalam masyarakat, lingkungan dan dunia. Ketujuh, integrasi niai dalam kehidupan nyata. Harto (????)

Internalisasi nilai-nilai tersebut dalam diri seseorang dapat dilakukan dengan beberapa pendekatan sebagaimana dikutip oleh Sukitman dari pemikiran Superka. Pertama, pendekatan penanaman nilai (Inculcation Approach). Pendekatan ini bertujuan menanamkan nilai-nilai sosial kepada peserta didik sehingga dapat diterima dan dapat merubah nilai yang tidak diharapkan menjadi nilai yang diharapkan. Metode pembelajaran dapat berupa penguatan persepsi positif dan negatif, permainan peran dan keteladanan. Kedua,pendekatan perkembangan moral kognitif (Cognitive Moral Development Approach). Tujuannya adalah mengembangkan tingkat berpikir peserta didik dalam membuat pertimbangan moral, menyelesaikan permasalahan-permasalah moral sehingga mampu membuat keputusan bernilai dan alasanalasan. Ketiga, pendekatan analisis nilai (Values Analysis Approach). Tujuan pendekatan ini adalah mengembangkan kemampuan berpikir logis dan rasional peserta didik dengan cara menganalisa masalah-masalah sosial. Jika pendekatan perkembangan moral kognitif lebih cenderung pada permasalahan moral perseorangan maka pendekatan analisis ini lebih cenderung permasalahan sosial. Pembelajaran dengan pendekatan ini dapat memakai metode kepustakaan maupun lapangan. Keempat, pendekatan klarifikasi nilai (Values Clarification Approach). Pendekatan ini dilakukan agar meningkatkan kesadaran nilai pada peserta didik dengan cara mengkaji perasaan dan perbuatan mereka sendiri. Hal ini dilakukan agar mereka memiliki kemampuan identifikasi nilai mereka sendiri dan orang lain, mengkomunikasikan nilai mereka 
secara jujur dan terbuka, mampu berpikir rasional dan memiliki kesadaran akan perasaan dan nilai dari tingkah laku mereka. Metode yang digunakan adalah dialog, diskusi, menulis dan sebagainya. Kelima, pendekatan pembelajaran bertindak (Action Learning Approach). Pendekatan yang lebih memotivasi peserta didik untuk melakukan perbuatan moral secara individu dan kolektif. Kesempatan ini mendorong mereka untuk menyadari eksistensi mereka sebagai makhluk individu yang tidak dapat berbuat bebas tak terbatas karena terikat oleh eksistensinya sebagai makhluk sosial. Sukitman (2016) Keenam, pendekatan transpersonal.Pendekatan ini bertujuan untuk mengembangkan kesadaran dan meningkatkan spiritualitas lebih tinggi. Dengan peningkatan tersebut peserta didik dapat berproses untuk menemukan jati diri dan aktualisasi diri menjadi orang yang bermanfaat.

Berbagai pendekatan diatas dapat diterapkan dalam kerangka menginternalisasi nilai-nilai kepada peserta didik. Proses terbentuknya nilai-nilai dapat melalui beberapa tahap; pertama, menerima nilai (receiving). Tahap penerimaan terbentuk ketika peserta didik mendapatkan stimulus dan fenomena dimana ia akan melihat nilai diluar dirinya dan memilih diantara nilainilai tersebut yang sesuai dengan dirinya. Kedua, menyikapi nilai. Setelah peserta didik menerima nilai, ia menyikapi penerimaan tersebut dengan kepatuhan (compliance), kesediaan untuk merespon (willingness to response), kepuasan dalam merespon (satisfaction in response). Ketiga, memberi nilai (valuing). Stimulus yang diberikan pada peserta didik dapat menjadikan mereka mampu menyusun persepsi tentang objek di tahap ini. Mereka kemudian menjadi percaya akan nilai tersebut, terikat pada nilai yang dipercaya dan memperjuangankannya. Keempat, mengorganisir nilai (organizing). Pada tahap ini peserta didik menata nilai yang diterimanya dari luar dengan cara mengkonsepsi nilai tersebut kemudian mengorganisasikan sistem nilai dalam dirinya sehingga ia mendasari perilakunya pada niai-nilai tersebut. Kelima, mengkarakterisasikan nilai (characterization). Tahap dimana peserta didik melakukan penerapan dan karakterisasi nilai dalam pribadinya sehingga ia dapat membuat sebuah kesimpulan bahwa nilai tersebut berpengaruh dalam dirinya serta memilih antara yang baik dan buruk.[11]

Metode atau strategi dalam mengimplementasikan berbagai pendekatan di atas adalah; pertama, pendekatan penanaman nilai. Metode yang diterapkan berupa pemodelan, penguatan positif dan negatif, bercerita. Kedua, pendekatan perkembangan moral kognitif melalui strategi studi kasus dan dilemma moral. Ketiga, pendekatan analisis nilai menggunakan metode pengujian prinsip, analisa kasus analog, debat, penelitian. Keempat, pendekatan klarifikasi nilai dapat diajarkan dengan metode mengumpulkan berbagai pertanyaan, memancing dengan kalimat yang belum tuntas, nilai kontinum (rangkaian kesatuan), pemeringkatan, setuju atau tidak setuju. Kelima, pendekatan pembelajaran bertindak dilakukan dengan proyek aksi terjun ke masyarakat. Keenam, pendekatan transpersonal dilakukan dengan metode relaksasi, meditasi, imajinasi kreatif dan kegiatan kesadaran diri. Reyes (2019)

\section{Kurikulum AIK di Perguruan Tinggi}

AIK di Pergurun Tinggi Muhammadiyah idealnya terbagi menjadi empat; AIK I, AIK II,AIK III, dan AIK IV. AIK I berisi aqidah dan insaniyah. AIK II berisi ibadah, akhlaq dan muamalah sedangkan AIK III Kemuhammadiyahan dan AIK IV adalah Islam dan ilmu pengetahuan. Jumlah sks minimal adalah 8 sks. Setiap masing-masing AIK bernilai 2 sks. Pengaturan dalam Pedoman Pendidikan AIK PTM ini dalam realisasinya dapat berbeda tergantung kebijakan masing-masing Universitas dan Program Studi.

Secara umum tujuan pembelajaran AIK adalah terdorongnya siswa untuk berproses menjadi insan yang bertaqwa, berakhlaq karimah, unggul dan berkemajuan dalam Ilmu Pengetahuan dan Teknologi. Adapun tujuan khusus AIK I adalah terbentuknya sarjana muslim yang mampu mengenal dirinya dan Tuhannya, mampu mengetahui misi dan tujuan hidupnya sesuai tuntunan al-Qur'an dan as-Sunnah. Kompetensi lulusan khususnya AIK I adalah memahami hakekat Tuhan, manusia dan kehidupan sesuai al-Quran dan Hadis dan ilmu pengetahuan. Materi perkuliahan meliputi Tuhan, manusia dan kehidupan. Tema yang dibahas antara lain hakikat manusia. Mode perkuliahan adalah perkuliahan regular dan tutorial atau asistensi. Sistem penilaian Keimana dan ketauhidan. Syirik dan Takhayyul, Bid'ah, Khurafat atau dikenal dengan TBC. Evaluasi pembelajaran terdiri dari empat komponen; Ujian tengah dan akhir semester (60\%), Tutorial (10\%), portofolio (10\%) dan Observasi $(20 \%)$. Secara terstruktur silabi AIK I dapat dilihat dalam tabel berikut; 
TABLE 1 | Silabi AlK 1 Pedoman AIK Majelis Dikti litbang PP Muhammadiyah

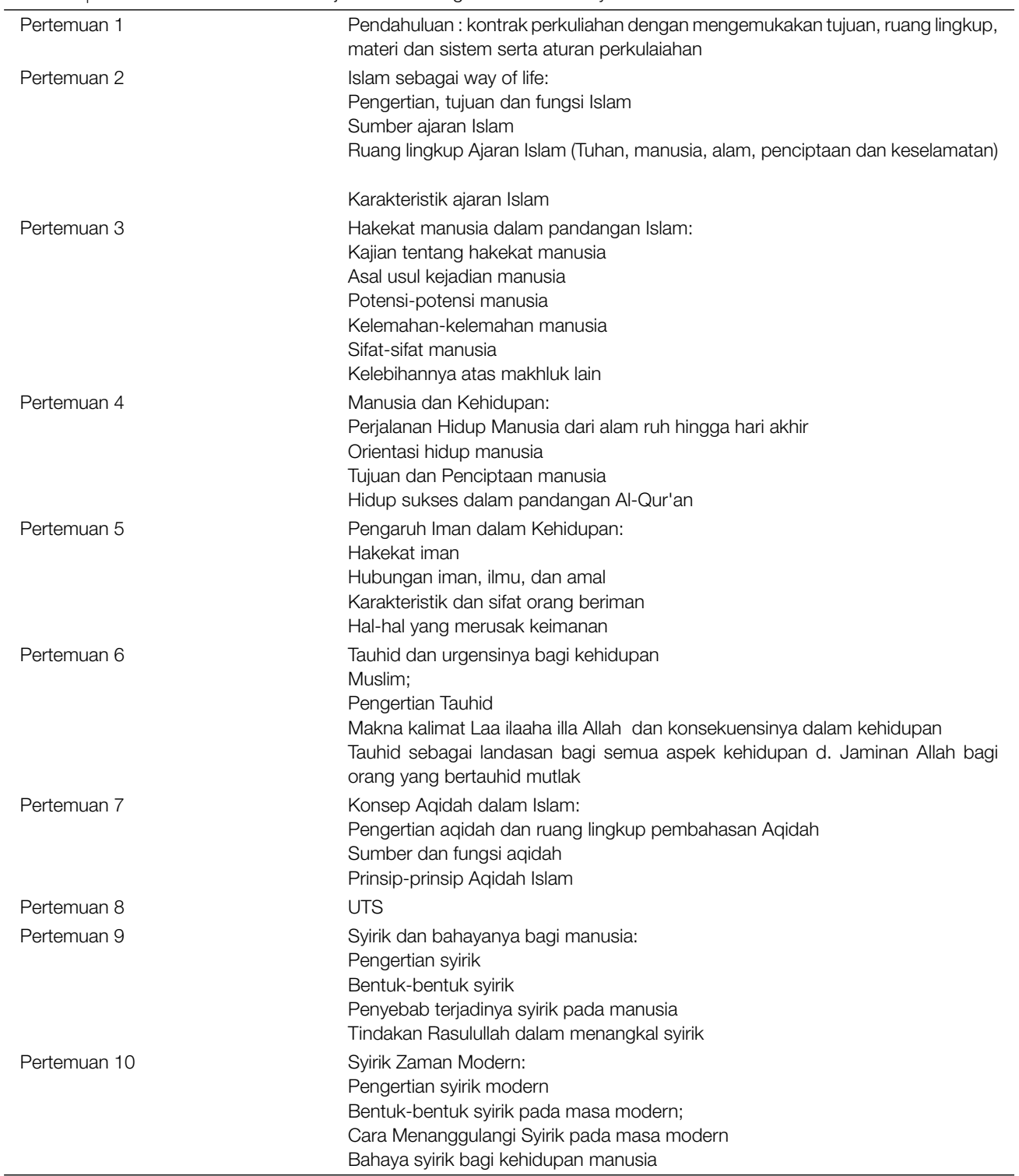

Dilihat dari tabel diatas tampaknya Majelis DIKTI PP Muhammadiyah belum memberikan materi dalam silabi secara lengkap jika dibandingkan dengan AIK II, III dan IV yang berjumlah 16 kali pertemuan sebagaimana jumlah pertemuan 2 sks di perguruan tinggi.

Secara konten materi, silabi AIK I mencerminkan adanya materi-materi keimanan dan kemanusiaan sebagaimana dituangkan dalam tujuan pembelajaran dan kompetensi lulusan AIK I yang telah disebutkan diatas. Hanya saja menurut pendapat penulis, silabi tersebut jika tidak dituangkan dalam rencana pembelajaran semester dengan metode dan strategi yang kreatif dan menarik akan menjadi pembelajaran yang verbalistis dan berorientasi kognitif semata sehingga tidak banyak memiliki dampak terhadap perilaku karena hanya dimensi pengetahuan saja yang ditonjolkan. Statemen ini seperti yang diungkapkan oleh Faridi tentang persepsi mahasiswa terhadap AIK bahwa pembelajaran AIK lebih cenderung pada pembelajaran Islam sebagai disiplin ilmu bukan Islam sebagai nilai sehingga kurang membangun penjiwaan nilai dalam kehidupan keseharian padahal peserta didik terutama mahasiswa prodi non Fakultas Agama Islam adalah peserta didik yang akan menjalani profesi sesuai bidang studi yang mereka pilih, tidak bertujuan untuk menjadi kyai atau ustadz an sich. Faridi (2010)Selain persepsi, mahasiswa juga memiliki harapan yang beragam terhadap perkuliahan AIK selain menghara- 
pkan bertambah wawasan dan pengetahuan. Mereka juga mengharapkan pembelajaran yang santai, tidak kaku dan membosankan juga mereka berharap dapat mengimplementasikannya dalam kehidupan sehari-hari. Nisa (2015) Atas dasar itu maka pendidik dalam hal ini dosen sangat berperan dalam menyusun silabi pembelajaran yang menarik, tidak dominan ceramah, tidak hanya sekedar mahasiswa diminta presentasi yang berujung pada pengetahuan kognitif saja tanpa memberikan efek dimensi emosional dan spiritual peserta didik. Pembelajaran AIK selayaknya tidak hanya melatih

kemampuan berkomunikasi mahasiswa melalui presentasi tetapi juga kemampuan mengalami dan menerapkan nilai-nilai dalam kehidupan mereka. Hal tersebut dapat dilakukan dengan menerapkan pendidikan nilai dalam pembelajaran AIK.

\section{Silabi Model Pembelajaran}

Pendidikan nilai dapat diterapkan dalam pembelajaran AIK dengan tujuan mendorong peserta didik untuk memiliki atau menguatkan nilai-nilai positif yang ada dalam diri mereka dimana pada dasarnya mereka telah mengetahui nilai-nilai tersebut dari pendidikan yang ditempuh sebelum jenjang perkuliahan dengan tetap mengarah pada tujuan pembelajaran dan kompetensi yang hendak dicapai. Berikut adalah tawaran model pembelajaran AIK I (Aqidah) dengan pendekatan pendidikan nilai berdasar nilai-nilai dalam teori living values education.

\section{KESIMPULAN}

Pendidikan dan pembelajaran AIK (al-Islam dan Kemuhammadiyahan) I diberikan dengan tujuan agar peserta didik menjadi sarjana mulim yang mengenal dirinya, Tuhannya dan hidup serta kehidupannya dapat dilakukan dengan menerapkan silabi pembelajaran yang berbasis pendidikan nilai dan teori living values education. Pendekatan pendidikan nilai meliputi; penanaman nilai (Inculcation Approach), perkembangan moral (Cognitive Moral Development Approach), analisis nilai (Values Analysisi Approach), klarifikasi nilai (Values Clarification Approach), bertindak dan berbuat (Action Learning Approach) serta transpersonal. Adapun nilai-nilai dalam teori LVE adalah kedamaian, penghargaan, cinta, toleransi, kejujuran, kerendahan hati, kerjasama, kebahagiaan, tanggungjawab, kesederhanaan, kebebasan, persatuan.

Model pembelajaran AIK I dengan pendekatan nilai lebih bersifat praksis dan implementatif sehingga pembelajaran tidak hanya bersifat monoton dimana dosen sebagai pendidik dan pembelajar hanya berorientasi pada pengetahuan kognitif peserta didik semata. Pembelajaran tersebut faktanya tidak member dampak yang berarti karena pengetahuan yang disampaikan dengan metode klasikal sejatinya dapat melalui media-media pembelajaran yang dapat dipelajari secara mandiri oleh peserta didik. Pendekatan ini melibatkan peran serta aktif dosen dan mahasiswa. Dengan pendekatan ini dosen dapat menanamkan nilai-nilai positif dalam pribadi peserta didik sebagai perwujudan keimanan dalam diri mereka seiring dengan bertambahnya keluasan pengetahuan tentang keimanan dan ketaqwaan serta nilai-nilai keIslaman sepanjang proses pembelajaran.

\section{UCAPAN TERIMA KASIH}

enulis mengucapkan terima kasih kepada panitia Seminar Nasional AIK diUniversitas Muhammadiyah Sidoarjo (UMSIDA). Semoga paper ini dapat menjadi tambahan referensi bagi Muhammadiyah khususnya, dan pendidikan Muhammadiyah umumnya. Masih banyak pekerjaan rumah berkaitan dengan pengembangan Mata Kuliah AIK dimasa sekarang dan dimasa datang

\section{REFERENCES}

20, U. U. P. N. (2003). Undang - undang Pendidikan No. 20 (Indonesia: Pemerintah Republik Indonesia).

Andriyani, A., Nata, A., and Saefuddin, D. (2014a). Implementasi Kurikulum Al-Islam dan Kemuhammadiyahan
(AIK) Melalui Model Student Centered Learning (SCL) di Program Studi Pendidikan Dokter Fakultas Kedokteran dan Kesehatan Universitas Muhammadiyah Jakarta. Ta'dibuna: Jurnal Pendidikan Islam 3, 141-141. doi: 10. 32832/tadibuna.v3i2.591. 
TABLE 2 | Silabi Model Pembelajaran AlK 1 (Aqidah)

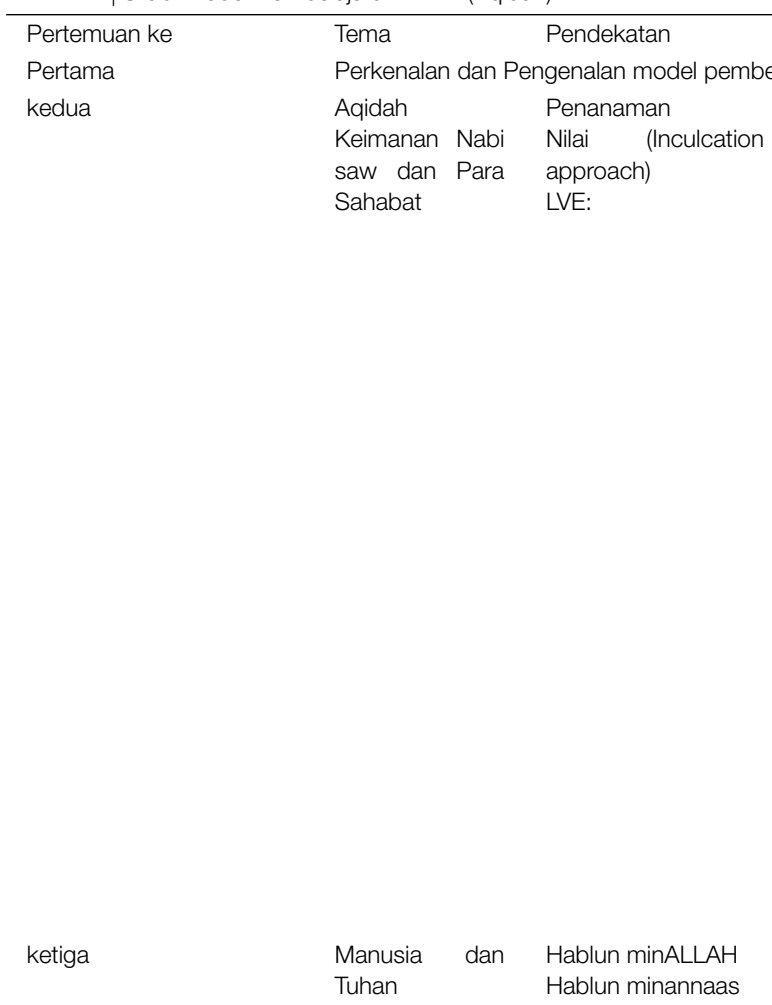

Metode dan Strategi aran

Metode: Pemodelan Penguatan nilai positif. Bercerita

Strategi :

Membagi kelas menjadi berkelompok dan meminta mereka membaca refrensi sejarah kehidupan Nabi saw dan Para sahabat tentang keimanan mereka.

Meminta perwakilan masing-masing kelompok untuk menceritakan kembali sejarah tersebut di depan kelas

Mendiskusikan

dengan temannya nilai-nilai Islam tentang hal-hal yang menguatkan dan melemahkan keimanan berdasar Al-Qur'an, hadis dan sejarah Islam.

Bertindak (Action learning approach)

Penanaman nilai

(Incalculation

approach)

LVE

Stimulasi

Refleksi Internal dan

Eksplorasi nilai-nilai dalam kehidupan

nyata

Ekspresi Kreatif

Pengembangan

keterampilan per-

sonal, emosiaonal

dan sosial

Integrasi nilai-nilai

dalam kehidupan

nyata

kelompok

Membuat aturan

hal-hal yang diper-

bolehkan dan yang

dilarang

Berkata baik (tidak ada kata-kata kotor, menghina, sombong

dII)

Sholat jama'ah di

masjid

Membaca al-Qur'an

Tahajjud

Sedekah

Kajian kelslaman

Melaporkan kegiatan

dan pengalaman

dalam bentuk

tertulis. Laporan

bersifat analitis kritis

solutif. keempat

Manusia

dan

Tuhan

Metode

Komunikasi

dan Diskusi di

masyarakat tempat

tinggal

Journal of Islamic and Muhammadiyah Studies | ojs.umsida.ac.id/index.phi\$thlttegi: Agustus 2020 | Volume 1 | Issue 2
Kerjasama

Tanggungjawa
Kejujuran

Kerendahan hati

Cinta

Kerjasama

Tanggungjawab

Kesederhanaan

Memberi penugasan

peserta didik untuk

terjun langsung ke 
mentasi Kurikulum Al-Islam dan Kemuhammadiyahan (AIK) Melalui Model Student Centered Learning (SCL) di Program Studi Pendidikan Dokter Fakultas Kedokteran dan Kesehatan Universitas Muhammadiyah Jakarta. Ta'dibuna: Jurnal Pendidikan Islam 3, 141-141. doi: 10 32832/tadibuna.v3i2.591.

Arifin, S. (2015). Rekonstruksi al-Islam KeMuhammadiyahan (AIK) Perguruan Tinggi Muhammadiyah Sebagai Praksis Pendidikan Nilai. Edukasi J. Penelit. Pendidik. Agama dan Keagamaan, 13, 219-219. doi: http://dx.doi.org/10.32729/ edukasi.v13i2.239.

Elihami (2017). Meningkatkan Hasil Belajar al-Islam dan KeMuhammadiyahan Melalui Kuis Dengan Umpan Balik Pada Mahasiswa Kelas A PGSD Di STKIP Muhammadiyah Enrekang. Safina 1.

Faridi (2010). Persepsi Mahasiswa Terhadap Mata Kuliah alIslam dan KeMuhammadiyahan (AIK): Internalisasi Nilainilai AIK Bagi Mahasiswa. Progresiva, 4, 67-67.

Harto, K. (????). Model Pengembangan Pembelajaran PAI Berbasis Living Values Education (LVE). Tadrib IV, 5-10.

Komalasari, K. and Sapriya (2016). Living Values Education in Teaching Materials to Develop Students ' Civic Disposition, $110-111$

Maunah, B. (2016). Implementasi Pendidikan Karakter dalam Pembentukan kepribadian Holistik Siswa. Jurnal Pen didikan Karakter V, 91-91. doi: 10.21831/jpk.v0i1.8615.

Muhammadiyah, P. P. (2011). Pedoman Pendidikan AIK al-Islam dan KeMuhammadiyahan Perguruan Tinggi (Yogyakarta: Pimpinan pusat muhammadiyah).
Nisa (2015). Ekspektasi Mahasiswa Terhadap Matakuliah alIslam dan KeMuhammadiyahan. Pros. Semin. Al-Islam dan KeMuhammadiyahan, 46-47.

Reyes, W. S. (2019). Approaches and Strategies in Teaching Values Education.

Subur, S. (1970). Pendidikan Nilai: Tela'ah tentang Model Pembelajaran. INSANIA : Jurnal Pemikiran Alternatif Kependidikan 12, 3-16. doi: 10.24090/insania.v12i1.215.

Sukitman, T. (2016). Internalisasi Pendidikan Nilai dalam Pembelajaran (Upaya Menciptakan Sumber Daya Manusia yang Berkarakter). JURNAL JPSD (Jurnal Pendidikan Sekolah Dasar) 2, 85-85. doi: 10.26555/jpsd.v2i2.a5559.

Conflict of Interest Statement: The author declare that the research was conducted in the absence of any commercial or financial relationships that could be construed as a potential conflict of interest.

Copyright (c) 2020 Nisa'. This is an open-access article distributed under the terms of the Creative Commons Attribution License (CC BY). The use, distribution or reproduction in other forums is permitted, provided the original author(s) and the copyright owner(s) are credited and that the original publication in this journal is cited, in accordance with accepted academic practice. No use, distribution or reproduction is permitted which does not comply with these terms. 